\title{
Socio-Spatial Relation in Small Island (Case Study: Karanrang Island, South Sulawesi, Indonesia)
}

\author{
Rahmi Amin Ishak ${ }^{1, *}$, Slamet Trisutomo $^{2}$, Ria Wikantari $^{1}$, Afifah Harisah ${ }^{1}$ \\ ${ }^{1}$ Architecture Department, Hasanuddin University, Gowa, 92172, South Sulawesi, Indonesia \\ ${ }^{2}$ Regional and Urban Planning Department, Hasanuddin University, Gowa, 92172, South Sulawesi, Indonesia
}

Received July 31, 2021; Revised October 21, 2021; Accepted November 11, 2021

\section{Cite This Paper in the following Citation Styles}

(a): [1] Rahmi Amin Ishak, SlametTrisutomo, RiaWikantari, AfifahHarisah, "Socio-Spatial Relation in Small Island (Case Study: Karanrang Island, South Sulawesi, Indonesia), "Civil Engineering and Architecture, Vol. 9, No. 7, pp. 2326 - 2337, 2021. DOI: 10.13189/cea.2021.090720.

(b): Rahmi Amin Ishak, SlametTrisutomo, RiaWikantari, AfifahHarisah (2021). Socio-Spatial Relation in Small Island (Case Study: Karanrang Island, South Sulawesi, Indonesia). Civil Engineering and Architecture, 9(7), 2326 - 2337. DOI: 10.13189/cea.2021.090720.

Copyright $\odot 2021$ by authors, all rights reserved. Authors agree that this article remains permanently open access under the terms of the Creative Commons Attribution License 4.0 International License

\begin{abstract}
Social interaction is an influential factor in shaping a community in a small island. There is a lack of study on how multi-ethnic groups of people living in a small island have shaped their community and maintained social harmony. This study identifies and analyzes the social interaction of residents in Karanrang Island in South Sulawesi, Indonesia. It focuses on how the social behavior of the residents has formed the spatial pattern of residential and community areas, including open spaces. Data of the residents' social behavior, activities, spatial layout of buildings, pathways, and major amenities were gathered from spatial mapping and on-site surveys. The analysis of socio-spatial patterns used the space syntax analysis method, namely Axial Analysis and Visibility Graph Analysis (VGA). The result shows that socio-spatial integration tends to occur in the irregular spatial configuration of residential areas, whereas socio-spatial segregation tends to occur in the regular spatial configuration. Furthermore, from the viewpoint of socio-spatial relation, the factors of activity location, residential density, and distance between houses significantly relate to social aspects such as community participation in social activities and willingness to assist neighbors. These findings are expected to provide consideration for the development of the socio-spatial structure that is suitable with the characteristics of small island communities, also to contribute to the sustainability of social order in the residential neighborhood of small islands.
\end{abstract}

Keywords Socio-Spatial Integration, Social Interaction, Spatial Configuration, Small Island Settlement, Space Syntax

\section{Introduction}

The various spatial configurations that exist in small islands are influenced by the social fabric of the local population. The strong spatial relationship between a community and a small island is indicated by their adaptation to the island's spatial conditions. The difference in the geographic influence of small islands with other landmasses causes differences in the way residents to conceptualize spatial islands [1]. Research by Illouz et al. [2] on Kangean Island and Sasongko [3] describes the spatial structure of the Sasak community settlements on Lombok Island. That research strengthens the view on how the influence of social aspects of society on the specific and different settlement environment patterns in each island condition, both the influence of the dynamics of the island's internal and external life.

As viewed from the socio-cultural aspect in general the locals have a good kinship and social interactions among the resident. Marriage between close relatives mostly happens in small islands that are remote and have limited access to transportation, and any kind of social interactions with outsiders. Usually, because of the small 
population, the locals are familiar with one another. People in small island settlements have unique spatial and social characteristics that are different from other terrestrial environments, it is shown by the adjustment and adaptation of the social system to the environment of the island. According to Grydehøj [1], island space is often associated with a distinctive culture. Territorial demarcation arising from island boundedness encourages distinctness, both islanders and people living on different islands, and incorporates distinct cultures within the island into a unified island identity [1].

Karanrang Island, as the focus of the study, is a dense and high residential growth island with the characteristics of a multi-ethnic population. The focus of the study is on the macro-spatial scope and meso-neighborhood, which consists of a collection of housing, environmental infrastructure, and social systems. Lefebvre in The Production of Space [4] explains that the spatial growth process has been shifted from land production-oriented as capital to space-oriented, which is conceptualized as a relationship of three major aspects; space, time, and social aspect. The baseline for several small islands in Pangkep Regency shows that the practice of "spatial production" has occurred in small islands limited by land availability. The dynamics of small island community life demands the need for space, which indicates the lack of shared space availability. However, small island communities tend to maintain similar rural characteristics and good social cohesion. Thus, this study focuses on the socio-spatial characteristics of the rural environment.

A Socio-spatial configuration is a form of order to explain differences in cultural existence between one social form and another that shows differences in people's lives and social existence. Socio-spatial configuration is also part of culture because it contains certain principles. In rural everyday life, the experience of spatial formation and configuration can be seen as a form of knowledge where we can read space and anticipate how life is in it. However, the relationship between humans and space is not only limited to culture and lifestyle but also affected by the changes and dynamics that occur in human lives. Different forms of social formation will produce characteristics of spatial configuration patterns, as various spatial arrangements require social formation to maintain it.

The spatial configuration of the residential environment reflects the forms of socio-spatial relations created from social interactions that develop in the community and the spatial pattern of the residential environment. In addition, aspects of the areas of the island and the physical condition of the environment also affect the way people interact so that they play a role in the formation of social and rural environmental characteristics (physical and non-physical) of small islands. The physical limitations of the island and the growth of the community indicate the density of the environment related to the environmental carrying capacity of the social aspect, while the non-physical setting of the environment is related to the adaptation of the community to the characteristics of the residential environment in social spaces indicating the level of social cohesion on the small island. Thus, the socio-spatial concept in small islands can be built from the relationship between the small island environmental context, with social and spatial aspects related to the field of environment architecture and social behavior.

This research is important because it raises the strategic issue of the characteristics of the maritime continent in the context of a residential environment on a small island with social dynamics of the community that appears in the social and spatial arrangement of the residential environment. The case of a small island in Pangkep Regency has been chosen to explore local wisdom of the small island residential environment, which has uniqueness, and peculiarities in the spatial structure and social life of the community, as well as adaptation to specific natural and environmental conditions. This small island study is expected to complement concepts, and theories in the field of architectural science that support social cohesion, and in particular, contribute to the development of socio-spatial theory for small islands.

The spatial configuration of the residential environment by the residents of Karanrang Island shows that some people represent it in informal and organic patterns. This pattern expresses space as a personal choice at a more micro level, related to the needs of social interaction and the behavioral background of the community. The Spatial pattern is conditions that adapt to a series of social spaces in the form of specific geometries, which exist at a time. Understanding the configuration of spatial patterns shows the relationships among elements or parts that formed and occur how the placement of the environmental element. Therefore, studying the spatial patterns of the residential environment is studying the physical and social design of the community.

\subsection{Social Characteristics of Small Island}

The physical growth and the dynamics of island life have resulted in various conceptions of "abstract space" as an alternative form of using "shared space". The concept of communal space on a small island is one of the binding elements in social interaction formation, which is the social strength of small island communities. The form of spatial configuration that tends to be dynamic allows the meeting spaces formation under residential areas, spaces between houses, roads, alleys, or residential alleys, on the beach, and the pier [5]. The diversity of physical arrangements of small island environments is also a part of the aspects that influence people's perceptions of the existing behavior, particularly social behavior.

A small island community is unique compared to the main island community in terms of social, economic, and culture. Horton [6] defines society as a group of humans 
who are; relatively independent, live together for a long time, inhabit a certain area, share the same culture, and do most of their activities in that group. Koentjaraningrat [7] interprets society as a community that consists of social units, including; crowd, class, social, social categories, social networking, group, community, and the community. The binding elements include; the orientation center, a means of interaction, interactivity, continuity, identity, location, custom systems and norms, traditional organizations, artificial organization, and leadership. The identity of the place is an important binding element to distinguish it from other social units.

Redfield [8] describes small island communities as isolated village communities with folk-society characteristics. The characteristics: 1) Has a distinctiveness; 2) Consists of several residents with a fairly limited number so that they still know each other as individuals with personalities; 3) Uniformity with limited differentiation (homogeneity); 4) The living needs of the population are very limited so all that needed can be met independently without depending on external markets (all providing self-sufficiency).

According to Koentjaraningrat [7], small communities can be divided into isolated communities (tribal communities) and peasant communities. Various types of small communities depend on the extent of the traits possessed. Further, Koentjaraningrat explained that the coastal communities and coastal isolated villages (small islands) types are characterized by their attitude, towards nature and people. Generally, they are subservient to nature, while some are trying to maintain harmony with it. There is a motivating view that there is power when subservience to nature.

\subsection{Socio-Spatial Relation}

Every social activity is bound to its space. Space is an integral factor in everything where humans do. This idea means that it is crucial to pay attention to space when exploring the built environment as another variable of the type of interaction it helps to shape human behavior. Paying attention to the spatial aspects of human life means that design and architecture play an important role in the way humans interact. Lefebvre [4] combines two ways of thinking about space to explain why a theory of the production of space is necessary. Space simultaneously exists at three levels: a) conceived, b) perceived, and c) lived space. Lefebvre formulates three characters of understanding space as both social process and social product based on these three dimensions of social production. The spatial structures of a given phenomenon are commonly investigated as an underlying cause, constructed outcome, or both.

In The Social Logic of Space Hillier, and Hanson [9] assume that social relationships are a function in which the shaping of space was based. Spatial arrangements with social activities in them have an impact that can be seen and measured. In explaining spatial and social problems, spatial forms have two meanings; the arrangement of humans in space and the relationships between humans in said space. Spatial configuration is known as a relationship between two spaces with third space considerations. Configuration is associated with the relationship between space that comes from the logic of space. This concept aims to show that the source of social behavior lies within the community itself and the specific forms required (not individuals), which can be achieved with the Model of Syntax. Thus, the spatial organization is not only a means of a group of individuals to shape society, but space has its laws and logic where it can also act as a barrier system in the community. Space is a form of language because the law does not depend on human desires to have a dialectical relationship with society [9].

Five elements of urban design by Kevin Lynch [10] can be used as the basis for the formation of the environment, namely; Paths (roads, sidewalks, walkways, and other channels through which people walk); Edges (perceived boundaries such as walls, buildings, and coastlines); District (a relatively large portion of an area that is distinguished by some identity or character); Node (focal point, intersection or locus); and Landmarks (an easily recognizable object that serves as a reference point).

From the study of architectural psychology, Laurens [11] describes a model of the integrative relationship between humans and the environment based on the following factors: 1) Behavior, 2) Behavior setting and 3) Characteristics of the behavior setting. Behavior is the result of interaction, simultaneously or separately, between the elements of the actor/person, and the environment is the background for the existence and activities of the actor/person. Behavior setting describes the complex relationship between actors/person and the environment, that shows some spatial characteristics as a background for behavior. The characteristics of these six behavior settings are territory (boundary of space), Core Area (core space), Distribution (distribution of space), Orientation (direction of space), Segregation (separation of space), and Integration (unification of space). The theory is related to the socio-spatial configuration of the residential environment on Karanrang Island.

\section{Materials and Methods}

Based on the pragmatism paradigm, the case of Karanrang Island uses mixed-method with a quantitative and qualitative approach. The aim is to identify and analyze the socio-spatial configuration using survey techniques with observation and interviews. The analysis technique uses spatial mapping, formal descriptive analysis (forms of the spatial pattern of the residential environment), and Space-Syntax (Axial Analysis and Visibility Graph Analysis) to explain the physical 
configuration of spatial and hierarchies related to social activities. The space-syntax analysis uses Depth Map-X software, with the type of analysis including; 1) axial analysis; connectivity, integration; 2) visibility graph analysis; visual integration, visual step depth, isovist analysis; 3) agent-based modeling; 2 Dimensions, and 3 Dimensions.

The discussion will begin with the results of settlement layout analysis at island macro-scale using the Space-Syntax method [9]. The determination of location spots is based on the results of the Space Syntax analysis that has a high level of integrity (global and local integration) to review the spatial relationships and social behavior of the community that occurs in these spots.

Hillier and Hanson [9] divide two stages of spatial analysis into: 1) Regulating humans in space people are interconnected, with certain conditions related to aggregation, separation, and movement patterns carried out by humans in various groups; 2) Organizing the space through building elements, boundaries, roads, markers, zones, and others which are physically definite patterns. From these two conditions, how the socio-spatial order is in an actual condition can be recognized.

The discussion of socio-spatial observations that occur in location will explain the factors that influence the occurrence of socio-spatial segregation and integration on Karanrang Island. The socio-spatial configuration on Karanrang Island is differentiated based on the spatial characteristics of the settlement and island environment, with macro island coverage. The boundaries of the location of social space are determined based on environmental clusters located in the edge and the middle of the island, with regular and irregular settlement configurations, also residential density. Residential density based on the Decree of the Minister of Public Works [12] divided into very low ( $<10$ buildings/ha), low (11-40 buildings/ha), moderate (41-60 buildings/ha), high (61-80 buildings/ha), very height ( $>81$ buildings/ha). The location spot is also determined based on the consideration of where social activities take place by considering the differences and diversity of social activities as the community adaptation to the physical structure of the island. The discussion of socio-spatial configuration at this stage focuses on social behavior, based on behavior setting theory, namely: distribution, orientation, territory, core area, segregation, and integration [11].

\section{Results and Discussions}

Karanrang Island is inhabited by $77 \%$ indigenous, a mixture of Buginese-Makassarese ethnic, and $23 \%$ of migrants who live side by side in one island region. In everyday life, the sea influences as the source of livelihood and transportation on the total population of 3,367 residents and 858 households (according to data Mattiro Bulu Village, 2019). The highest population level of education, generally in prime $(69 \%)$ and middle $(23 \%)$. The livelihood of the head of the family is generally a fisherman with an average monthly income of 1 million 1.5 million rupiahs. High population growth indicates a "spatial production" or increase of residential yearly that impacts the density of the island and the reduced availability of social spaces that are part of community life on the small island.

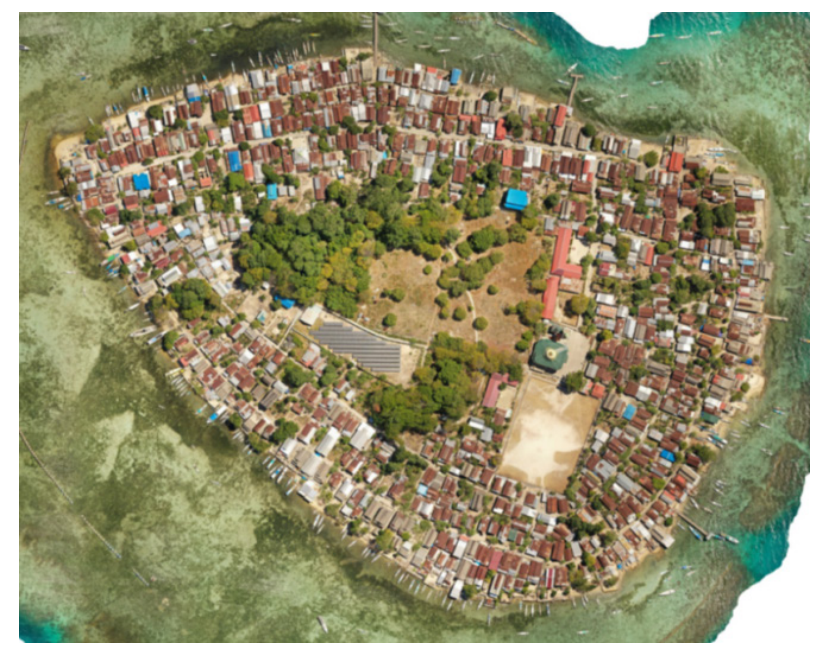

Figure 1. Aerial view of Karanrang Island (August, 2020)

Figure 1 shows the aerial view of Karanrang Island, as the case study of socio-spatial, was chosen based on the specific location. The life of the island community tends to be isolated and marginalized from its mainland island, their ethnic diversity, and the tendency of "space production" practices indicate the occurrence of island density. Karanrang Island is part of the Spermonde Islands, located in the middle between small islands scattered in the northern and southern islands of Pangkep Regency, South Sulawesi, Indonesia. Predominantly, the southern islands of Pangkep are inhabited by Makassarese. Formerly belonging to the Gowa kingdom, the island's name generally begins with "Po-" which means an island, such as; Polo Wali, Polo Kulambing, Polo Laiya, Polo Pala, Polo Langkadea, Polo Karanrang. The northern islands of the Pangkep District are dominantly inhabited by the Buginese. Formerly included in the territory of the kingdom of Bone, the name of the island generally begins with "Sa-," such as; Saugi, Sapuli, Satando, Sabutung, Sabalana, Saranti, Salemo. 
Table 1. Figure ground and facilities layout analysis

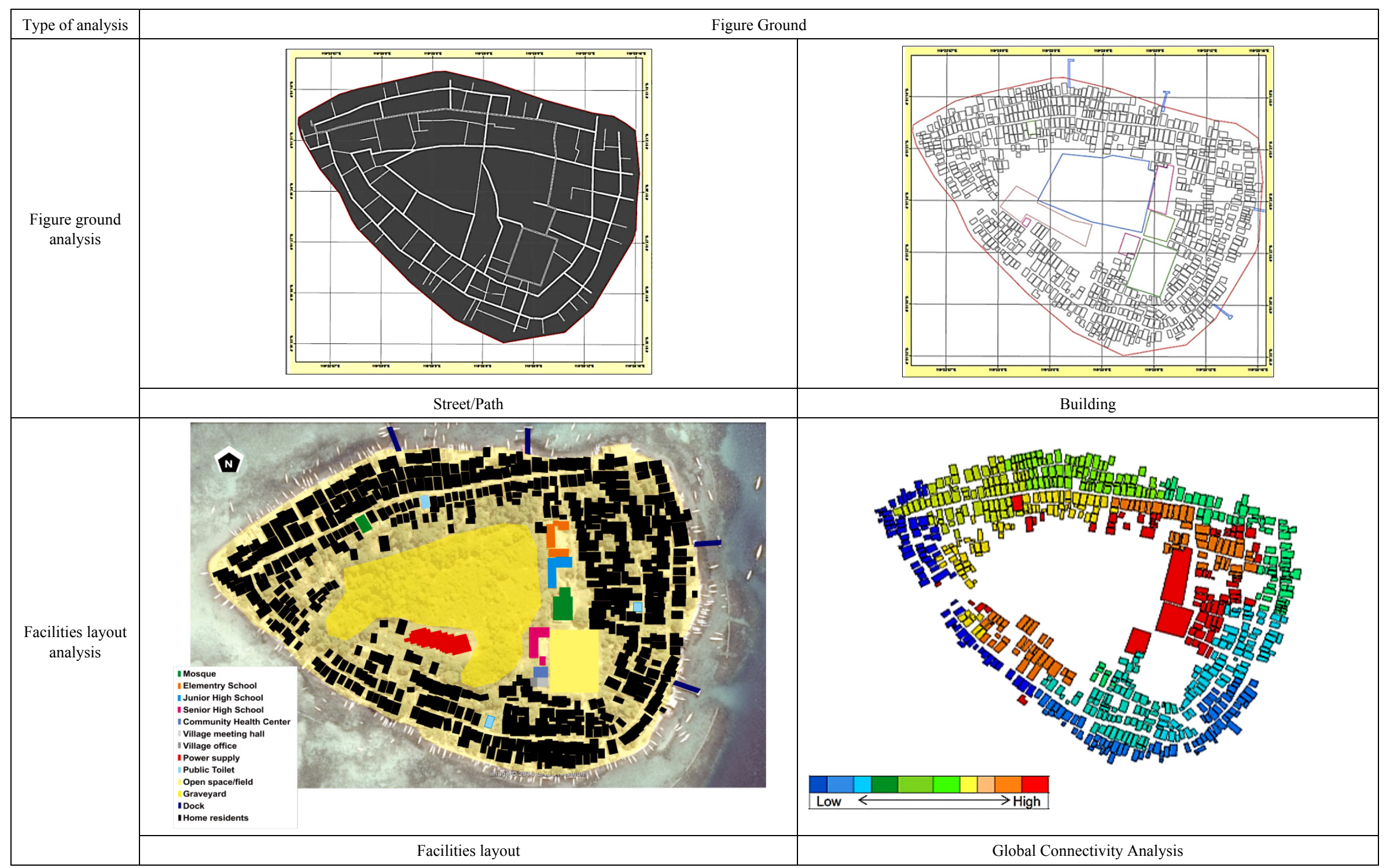




\subsection{Facilities Layout}

Table 1 shows the analysis of street/path and building ground figures and the location of environmental facilities. Dominantly community houses are located from the edge of the island to the middle part of the island, while the dominant main facilities are in the middle of the island. Dominantly building connectivity is high in the eastern and northern parts of the island. They are housing close to the facilities. Meanwhile, in the western and southern parts of the island, the level of connectivity tends to be low due to the distance to the main facilities (mosques, schools, offices) which are, quite far. The closer the dwelling is to environmental facilities, the higher the level of connectedness and accessibility of the environment [13].

The open space on the island is located in the center, while the area around the residence tends to have no specific open space since it's only formed due to the residential configuration. Most of the time, people do not gather in the center of the island because it is a sacred grave area. Only at certain times, the open space area in the center of the island is crowded, mostly during traditional fishing and death rituals. Another open space area located in the center of the island is a soccer field. The community uses it for sports activities and celebration ceremonies. This area tends to be visited by residents in the morning and evening. The lack of shade plants around the field has caused people to be reluctant to do any activity in this area during the day.

The social activities of the residents spread along the circulation path/street (dynamic space) in the middle of the island (Figure 2). The spatial configuration of housing in this environment is linear. From further observations, certain areas such as mosques and the surrounding environmental facilities (schools, public toilets, stalls) are driving forces for community social activities on Karanrang Island. This can be seen from the frequency of activities at the mosque. The community considers that formal socialization activities are always at the mosque. From this condition, it can be stated that the mosque area and its surroundings are the centers of community social activities. Karanrang Island has educational facilities at the level of Elementary School, Junior High School, and High School, which are generally the center of children's activities in the morning until noon. The location of educational facilities is generally $(77 \%)$ close to residential areas $(50-100 \mathrm{~m})$.

The axial analysis is used to predict the potential of meetings in the space. It is directly linked to the presence of people, predicts how space is connected with other spaces in its surroundings [9].

On the edge of the island, community activities take place around residential areas and the beach (organic space). The pattern of community activity tends to follow the configuration of the building mass and the coastal boundary (Figure 3 ). The layout of the buildings that tend to be irregular provides dynamic spaces for the community to interact. People interpret the area as a quiet and relaxing resting place to spend with family and close neighbors. The territory in this area is characterized by temporary benches under trees called bale-bale, boats, and fishing gear. People seek open space because of their need for social interaction [13]. Open space is a place for chance meetings and potential interactions with people [14].

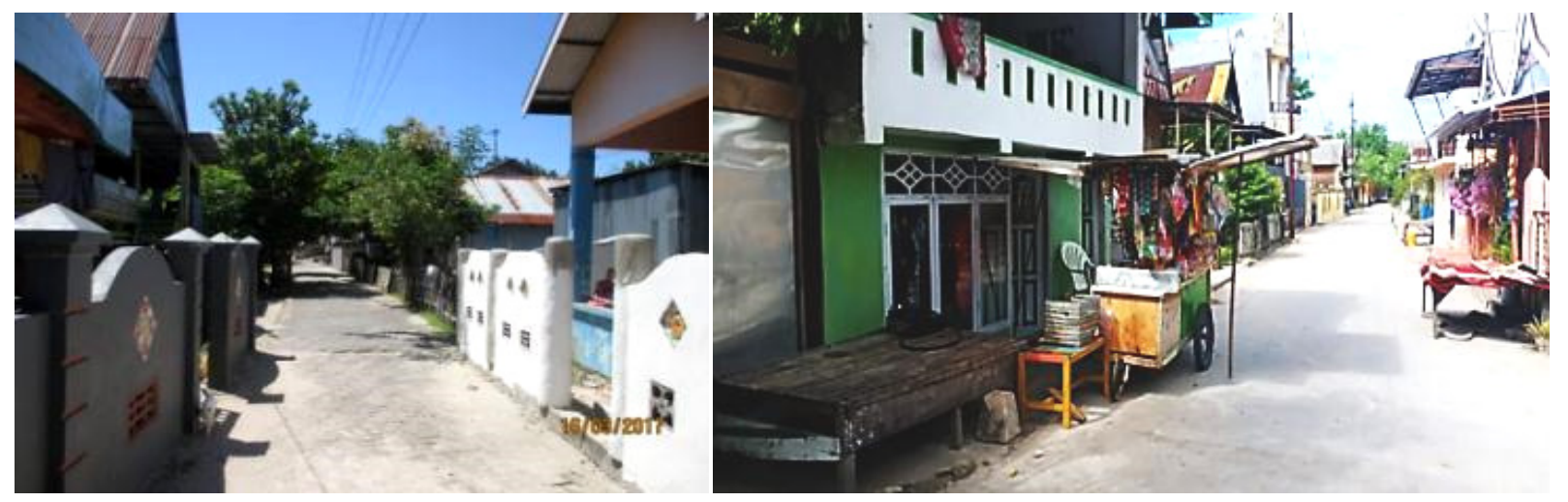

Figure 2. Residential neighborhood on the middle of Karanrang Island (August, 2020) 


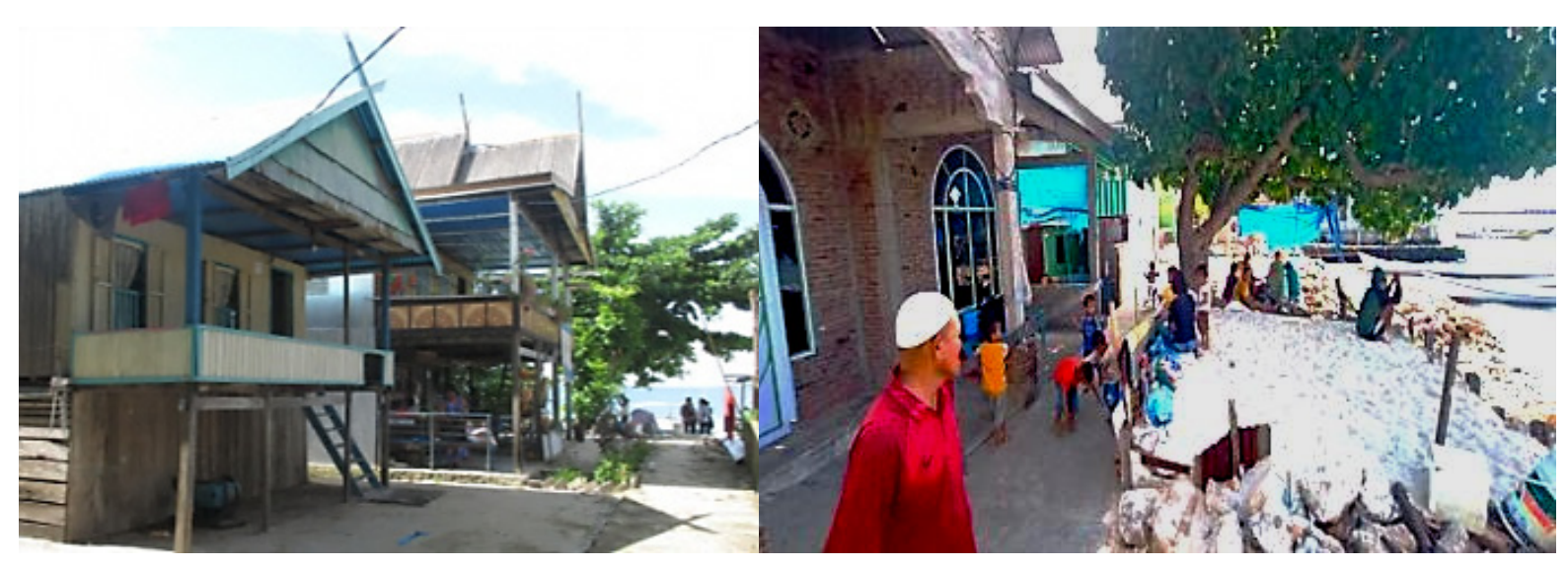

Figure 3. Residential neighborhood on the edge of Karanrang Island (August, 2020)

Table 2. Street/Path analysis

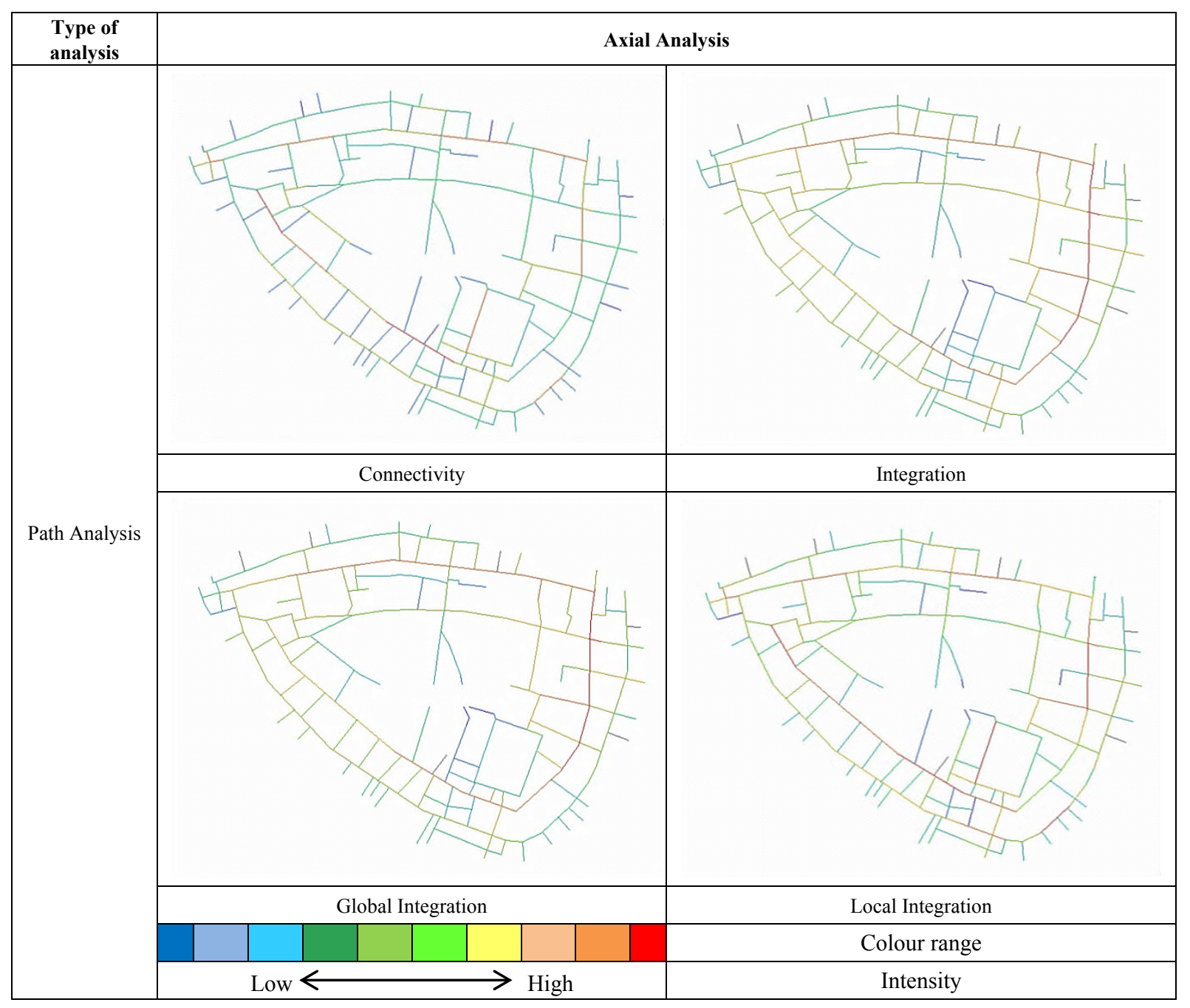

\subsection{Axial Analysis}

Table 2 shows the spatial relationships and social behavior based on axial analysis. The red lines indicate a high level of connectivity (accessible) and integrity (movable) on several main roads. The greater integration of the space, the more people will appear in it. Less integration means less human presence. For this reason, integration is sometimes called accessibility. Space with high connectivity means it has good accessibility to be accessed from the variety of spatial or streets/paths that link directly. 
The axial analysis also shows potential movements globally and locally. Local integration measured the scale of pedestrian movement, and Global Integration measured throughout the system (vehicular movement; bicycle and motorcycle). The results of observations show that environmental facilities that are often accessed by the public generally located on the main road. However, some environmental facilities can be used by local movement (according to the walkability distance).

Furthermore, from the results of the axial analysis, four location spots were determined to have high levels of global and local integration and represent regular and irregular configurations, as well as different physical settings (the edge of the island and the middle of the island). The pattern of the space and the physical setting has a different character of movement and visibility and affects the setting behavior. Spots A and B represent the character's spatial configuration on the edge of the island, and spots $\mathrm{C}$ and $\mathrm{D}$ represent the spatial configuration in the middle of the island (see Figure 4).
The four spots analyzed are similar in their syntactic values, where the global and local integration values are practically identical (see Figure 4). Nevertheless, at a fine level of distinction, spots $\mathrm{C}$ and $\mathrm{D}$ can be described as more integrated globally. Spot B is more integrated locally, while spot A is the most segregated both locally and globally. The most accessible spots seem to be spots $\mathrm{C}$ and $\mathrm{D}$, while $\mathrm{B}$ is a transition situation, and spot $\mathrm{A}$ is the furthest to reach. Field observations show that the level of integration is influenced by environmental facilities' presence, the type of street, and its connection to the main jetty. However, people in spots $\mathrm{C}$ and $\mathrm{D}$ tend to see the street as a busy one for the public, so that people generally build fences to emphasize their territory and privacy (Figure 4). It also affects the level of community social interaction. A study about space syntax [16] shows that the areas prone to crime are the areas that have a high degree of integration and are easily accessible to the public, which also triggers social segregation.

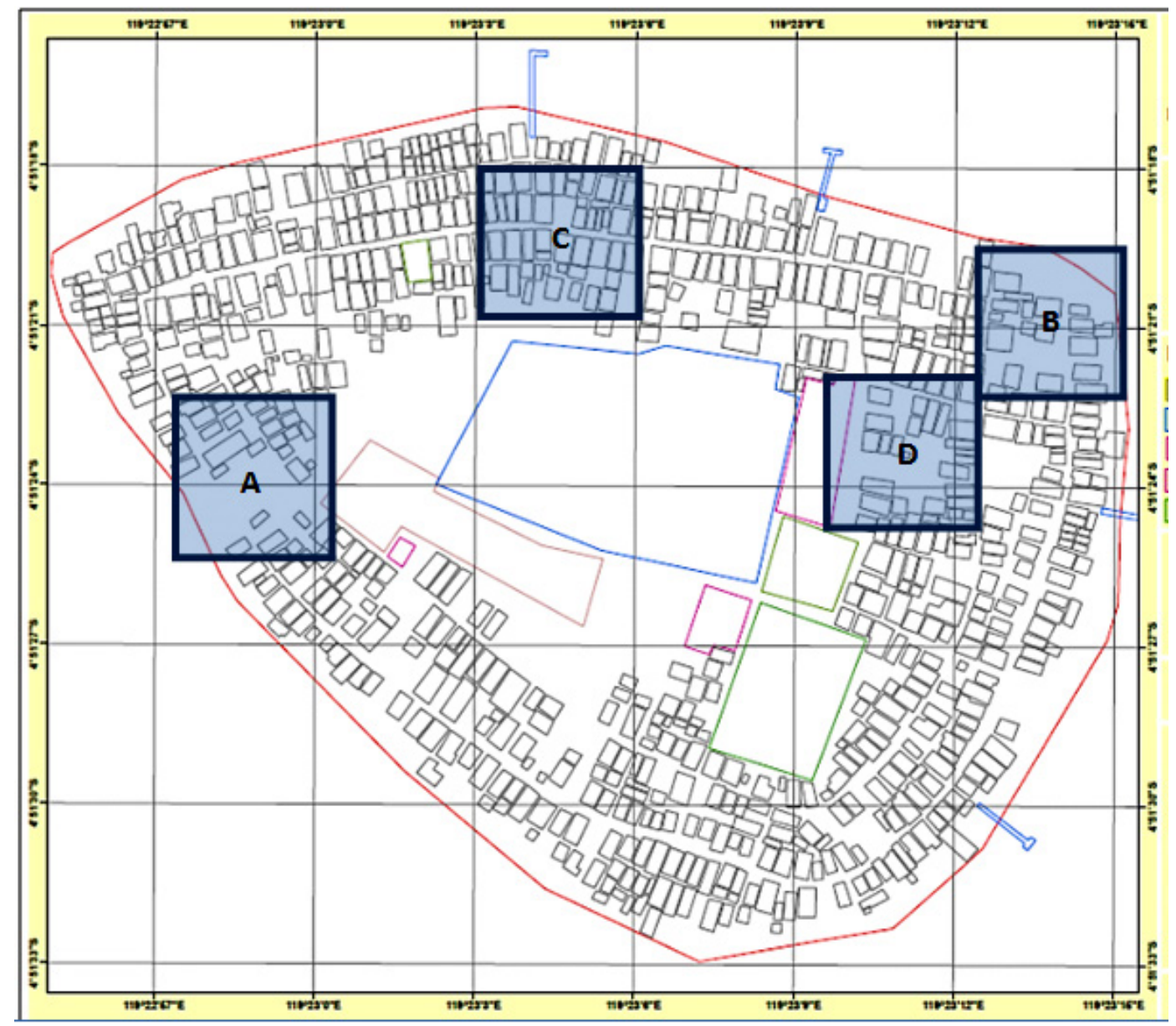

Figure 4. Location of research spots on Karanrang Island 
Table 3. Building Analysis

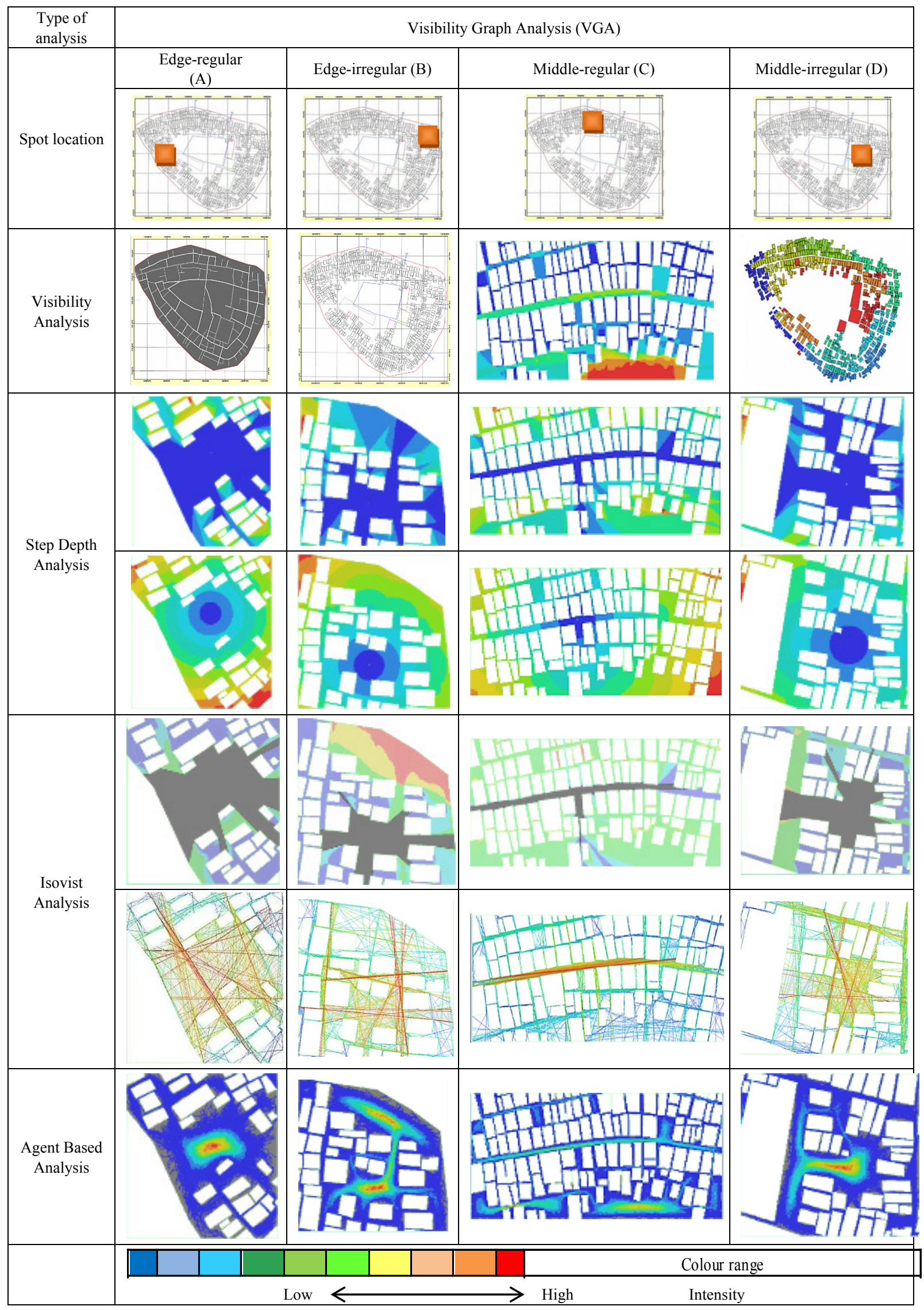




\subsection{Visibility Graph Analysis}

Further to axial analysis, analysis of the configuration of the building is also carried out at the level of visibility, how visual connect spaces. Visual connection indicates visual integration, where space is created visually. Visual integration means how visually connected are all spaces in the footprints. Space is created by a visual barrier such as building and vegetation.

The results of the Visibility Graph Analysis (Table 2) show that settlements on the edge of the island tend to have a good visual connection compared to dwellings in the middle of the island with regular residential configurations. In beachfront residences, people tend to gather in areas that are visible and directly connected. These open spaces (share space) are characterized by the environmental elements of trees, seating, and gazebos. Whereas in regular residential configurations with low visibility, there tend to be pockets of space used as shared facilities. In this regular residential configuration, residents generally gather in environmental facilities, such as prayer rooms/mosques, public sanitation facilities, stalls located on the terraces of residents' houses, and roads as part of the gathering place.

Step Depth Analysis shows the stage of the visual range experienced by a person at a certain point if they are in a different spatial configuration. This analysis includes angular step depth and metric step depth. Angular step depth shows the visual stage based on the viewing angle range (using $360^{\circ}$ angles). Based on this analysis, residential configurations on the edge of the island with open spaces tend to provide easy viewing angles coverage in different directions, thus providing good spatial integration. The residential configuration in the middle of the island is limited to the visual of the road, which is bordered by fences and buildings.

Isovist analysis shows the visual volume of space that appears from a certain point in space. Like the light illuminating space, the observation point is in an open space in a residential area. The isovist level of 3-dimensional space is influenced by its convex/non-convex shape, depth, size, and centricity. The limited point of view (visual) factor in regular housing tends to have implications for the sense of enclosure (environmental closure) or the feeling of being in the room. The presence of fences, guardrails, and roads/alleys in this environment gives the impression of an intimate scale. The configuration of environmental elements with visual characters that are enclosed in dwellings in the middle of the island (linear-regular) gives the perception of confinement. On the other hand, the configuration of large openings with visual inclination from all directions reduces the impression of an enclosure in a beachfront residential environment. Mikellides and Byron [17] explained the physical condition of space factors that affect psychology, including the closedness of space, environmental potential, and social status. Mikellides reveals how the configuration of space elements and visibility affected the perception of the closedness of space.

Agent-Based Analysis shows the tendency of people to move in a spatial configuration. People tend to move towards open spaces without visual and physical barriers, like water flowing in space. The same thing happened in residential neighborhoods on the edge and the middle of the island, with different configurations affecting people's tendency of movements on the island. People tend to choose to gather in open space areas that are visually and physically integrated with their residential units.

\subsection{Socio-Spatial Relation Analysis}

The following discussion is an analysis of socio-spatial relations by correlating between social interaction data and spatial characteristics in residential neighborhoods on the edge of the island and in the middle of the island. The results of the analysis are then compared with the syntax analysis map (axial analysis and visibility analysis). The unit of analysis of social interaction is taken from people's opinions about social interaction, while the unit of spatial analysis is based on observations in the field.

Based on the spatial layout, the activities of receiving neighbors or guests tend to be carried out on irregular spatial configuration. Besides, activities as such are related to the distance between houses as well. Houses with 1-2 meters distance to another tend to have a more dominant interaction with neighbors by $77 \%$ compared to those with 3-4 meters distance between them. Regarding the building's distance, receiving neighbors tend to happen in buildings with 1-2 meters distance $(69 \%)$. The activity was also significantly related to neighbors or family gathering places that tend to conduct around the house (77\%).

Doing recreational activities together is one form of interaction with neighbors. There are $77 \%$ of these activities. Most of the time, it is held near the house and is closely related. The distance between the house and the road is also related to the intensity of doing recreational activities with neighbors. Houses with 1-2 meters distance from the road tend to be more intense in doing these activities than those with 3-4 meters distance or more.

The activity of assisting neighbors tends to be related to the layout of housing. There is $54 \%$ of activities held by the community in settlements with irregular layouts houses. Moreover, the distance between buildings is also significantly related to the habit of assisting neighbors. A $77 \%$ of settlement residents with 1-2 meters distance between buildings help their neighbors more often than residents with the distance between buildings 3-4 meters. The community participated in social activities that were significantly related to the place to carry out the activities. Social activities by $69 \%$ happen in the front yard, $23 \%$ are in the open space. 
Table 4. Socio-spatial relation in Karanrang Island

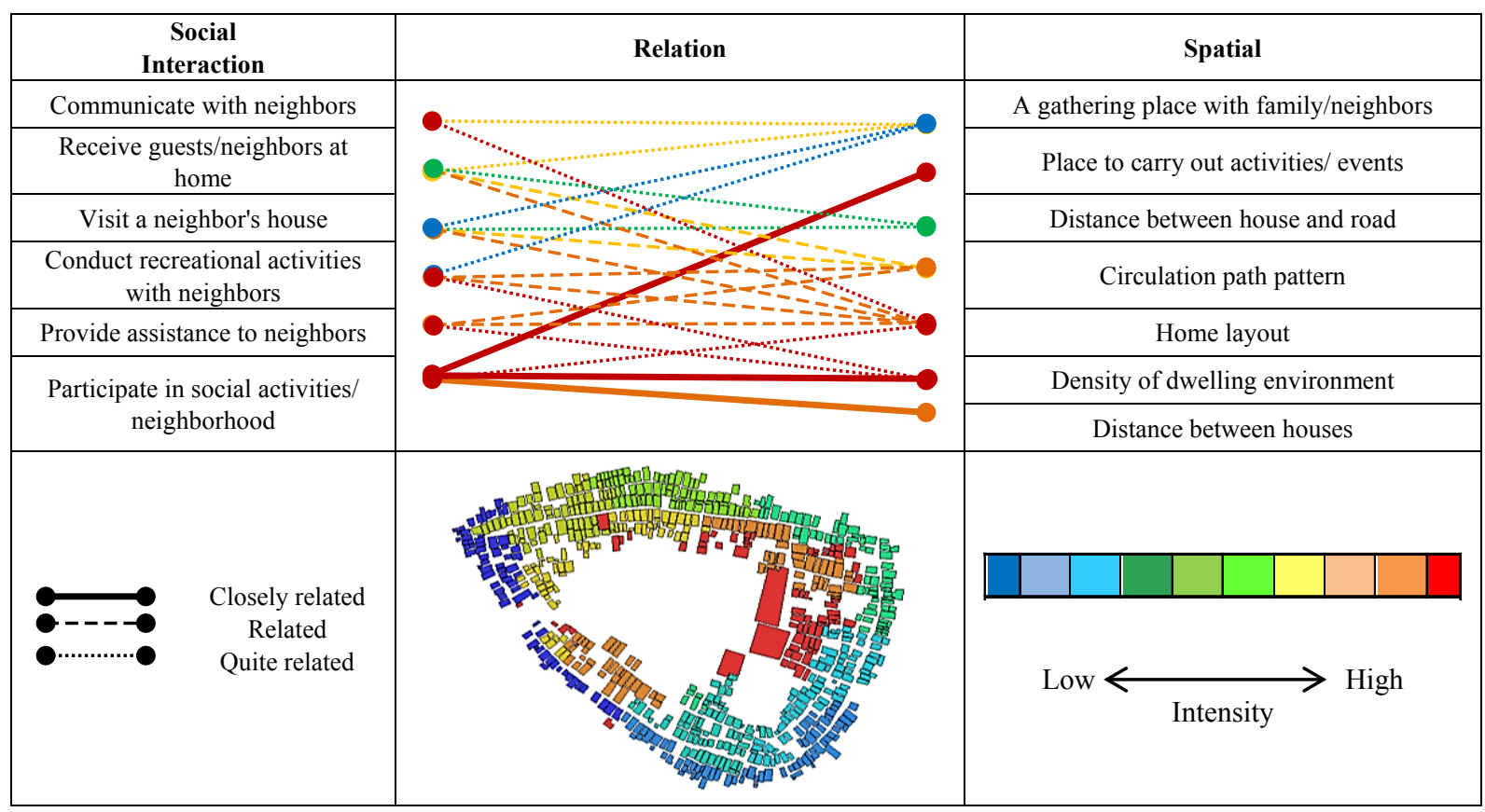

Table 4 shows the socio-spatial relations that occur on Karanrang Island. From the social interaction, it appears people tend to interpret social participation activities in spatial conditions based on; the location where it takes place, the density of the residential environment, and the distance between houses. These conditions tend to occur in residential environments that are irregular and dense, with an intimate environmental scale. Based on the road and building syntax map, residential neighborhoods on the edge of the island have a high level of local integration. Meanwhile, residential neighborhoods in the middle of the island have a high level of global integration.

Therefore, it can be concluded that residential neighborhoods on the edge of the island with irregular residential configurations tend to form clusters (local integration) that have good social interaction. Meanwhile, the regular residential neighborhoods in the middle of the island tend to create social segregation. People tend to be attracted to being on the edge of the island that has the characteristics of a coastal environment, which has a visual appeal, and a beach soundscape, so that a shared space is formed on the beach. Meanwhile, people in settlements in the middle of the island tend to form social spaces in the area of environmental facilities, roads/alleys, and spaces between houses, which are temporary, dynamic and move from place to place following visual and audial factors, such as the sound of the call to prayer, the sound of the school bell, the voice of the seller, conversational sounds, etc. In line with Carlson and Buskist's explanation, the existence of people's interest in the use of space is caused by the intimacy factor, including the articulation of environmental elements with distance and intimate scale [18]. These factors affect the repetition of memorable events (positive) on a person or group of people. This effect will result in the desire to repeat the memory. That is why people will tend to remember memories related to space. It explains why there are crowded public spaces while there are public spaces that are not [18]. To be more specific, a study of socio-spatial is needed on the scope of the messo and micro residential environment.

In terms of Lefebvre's theory of space [4], which starts from the basic concept of the first space (physical-perceived) and the second space (psychic-conceived), where the configuration is, at least, understood as the relationship between the two spaces by considering the third space (living space). However, in this study, spatial complexity does not only take the third space into account. The various relations between spaces of social interaction are also studied [19].

\section{Conclusions}

This study finds out that the relation of social interaction and spatial configuration in Karanrang Island indicates that the irregular residential environments on the edge of the island correlate with the value of spatial integration. On the other hand, the regular residential environments with high spatial integration values tend not to correlate with social interactions. The global and local integration values assigned to spatial units correlate with community survey information in the spot of each location and with the frequency of social interactions that occur. It shows that the organic-irregular spatial configuration (on the edge of the island) tends to have better social 
interaction compared to the linear-regular one (on the middle of the island). In social life, the relationship between residents and the residential environment depends on movement flow phenomena, boundaries and the distance between two places, and spatial visibility concepts.

This concludes that socio-spatial relations in small island that tend to be natural, influenced by the characteristics of the physical setting; the place for activities, the density of the living environment, and the distance between houses, as well as the characteristics of the non-physical setting: visual, movement, and audial. The physical characteristics of small islands that are rich in visual soundscapes and the activities of inhabitants provide a variety of dynamic shared spaces, such as shared spaces on the beach, streets/alleys, and spaces between houses. This conclusion is expected to enhance the theory of spatial configuration in terms of social and spatial aspects. It reveals a novelty in the architectural research on the relation of spatial configuration and social interaction, particularly on small island settlements pertaining to local wisdom in the social harmony of small island communities and their residential environments.

The above conclusion enriches the theory of social logic of spatial configuration proposed by Hillier and Hanson [9] that links to various analyses of the psychological aspects of architecture.

\section{Acknowledgements}

We are very grateful to Prof Ismail Said from Universiti Teknologi Malaysia (UTM) for his guidance during the sit-in study, our native resource Mr. Mursalim who provided information and assisted us during the survey, and to the residents of Karanrang Island who welcomed us in conducting this research. We also thank Mr. Sambar who assisted us in the field survey and GIS analysis, as well as fellow students of the Department of Architecture, Hasanuddin University, batch 2013 who have been involved in this research. Thankfulness to Mr. Ruslailang for spend time discussing the local concept of Buginess ethnic.

\section{REFERENCES}

[1] Grydehøj, A. "Islands of indigeneity: Cultural distinction, indigenous territory," Wileyonlinelibrary.com/journal/area, page 14-22, 2018. DOI: 10.1111/area.12520.

[2] Illouz, C. "Kangean Islands: Applied Research for Development”. Jakarta: Popular Library Gramedia (KPG),
2013.

[3] Sasongko. "Karangsalah and Segenter Residential Space Structures in Bayan Village," Journal of Architectural Engineering: Dimension. Edition: 20 (1), 2005: 16-25.

[4] Lefebvre, H. The Production of Space. Oxford, UK \& Cambridge, USA: Blackwell, 1991.

[5] Wikantari, R et al. Finding Children's Playing Place in Lae-Lae Island, Makassar. Yogyakarta: Proceedings of 2nd International Conference on Architecture and Planning (ICIAP 2), GadjahMada University, 2014.

[6] Horton, Mark. Architecture and Order, Chapter: Swahili Architecture, Space And Social Structure. New York: Routledge. 1994.

[7] Koentjaraningrat. Introduction to Anthropology. Jakarta: Rineka Cipta. 1990.

[8] Redfield, R, and Wilcox, C. Social Anthropology, Chapter: The Folk Society. New York: Routledge. 2008.

[9] Hillier, B, and Hanson, J. The Social Logic Space. Cambridge University Press, 1984.

[10] Lynch, Kevin. "The Image of the City". Massachusetts, and London, England: The M.I.T. Press Massachusetts Institute of Technology Cambridge. 1960.

[11] Laurens, J. Marcella. Architecture of Human Behavior. Surabaya: PT. GramediaWidiasarana Indonesia. 2004.

[12] Decree of the Minister of Public Works. No. $378 / \mathrm{kpts} / 1987$.

[13] Ishak, R.A., Trisutomo, S., Wikantari, R., andHarisah, A. "Socio-Spatial Typology in Karanrang Island." International Conference on Architectural Education in Asia (eduARCHsia 2017) Vol.41. Yogyakarta: Universitas Islam Indonesia (UII), 2018.

[14] Marcus, C, and Francis, C. People Places: Design Guidlines for Urban Open Space. USA: John Wiley \& Sons, 1997.

[15] Drucker, and Gumpert. Public Spaces and the Right of Association. Free speech year book, 1998.

[16] Hillier, B., and J. Hanson. Space is the machine: a configurational theory of architecture. Cambridge.: Cambridge University Press, 1996.

[17] Mikellides, and Byron, "Architecture for People",London.: Studio Vista Book, 1980. Published by Holt \& Company, Henry, 1980, ISBN 10: 0030574919ISBN 13: 9780030574917

[18] Carlson, N, R., and W Buskist. Psychology: The Science of Behavior. Britania Raya: Allyn and Bacon., 1997.

[19] Ruiz, Javier. "A Theory of Socio-spatial Integration: Problems, Policies and Concepts from a US Perspective." International Journal of Urban and Regional Research, Volume 37, No. 2, Pages 388-408, March 2013. 